\title{
Enzyme Activity of 3ß-HSD and 11ß-HSD as Important Indicators of Steroid Bio-Synthesis and Inactivation in Preterm Infants
}

\section{Jan De Laffolie ${ }^{1 *}$, Lars Kästner ${ }^{1}$, Michaela F Hartmann², Stefan A Wudy², Birgit Kamp- schulte', Bianca Grofer ${ }^{1}$, Rolf-Hasso Bödeker ${ }^{3}$ and Matthias Heckmann ${ }^{4}$}

${ }^{1}$ Division of Neonatology, Department of General Pediatrics and Neonatology, Justus Liebig University Giessen, Germany

${ }^{2}$ Division of Endocrinology, Steroid Research and Mass Spectrometry Unit, Department of General Pediatrics and Neonatology, Justus Liebig Giessen, Germany

${ }^{3}$ Institute of Medical Statistics, Justus Liebig University, Germany

${ }^{4}$ Department of Neonatology and Pediatric Intensive Care, University of Greifswald, Germany

\begin{abstract}
Background: The fetus lacks 3ß-hydroxysteroiddehydrogenase (3ß-HSD) activity until the last trimenon (requiring placental progesterone) and active cortisol concentration is regulated by synthesis through 11ß-hydroxylase and inactivation by $11 ß$-hydroxysteroiddehydrogenase (11ß-HSD). In this study we estimate enzyme activity of $3 ß-H S D$ and $11 ß-H S D$ in preterm infants.

Method: A 24-hour profile of glucocorticoid metabolites was obtained in the urine of 61 preterm infants of $<28$ wks GA and 81 preterm infants $>=32$ wks GA using gaschromatography-masspectrometry (GC-MS). Enzyme activity was calculated using substrate/product ratios.

Results: There was no influence of severity of disease on enzyme activity on day 3 and week 3 of life, but significant influence of postnatal age and gestational age ( $\mathrm{p}=0.019 ; \mathrm{p}<0.001)$. Patients $<28$ wks GA in contrast to the patients $>=32$ wks displayed a significant increase in 3ß-HSD activity from day 3 (median 11.73; IQR 6.20 - 18.53) to week 3(7.69; 4.70 9.75). 11ß-HSD activity decreased postnatally until the third week of life to the level of more mature patients.

Conclusion: Severity of illness had no significant influence on $3 ß-H S D$ and $11 ß-H S D$ activity in preterms. Instead there is significant increase in $3 ß-\mathrm{HSD}$ activity in preterms $<28 \mathrm{wks}$ during the first three weeks postnatal and reduced inactivation of active cortisol.
\end{abstract}

\section{Introduction}

Immaturity of steroid biosynthesis is assumed to cause relative adrenal insufficiency in preterm infants [1]. Even if the rate-limiting step is still unclear the current knowledge allows identifying several candidate enzymes [2].

The most interesting enzyme is the $3 ß$-hydroxysteroiddehydrogenase (3ß-HSD), which is necessary to produce cortisol from cholesterol or pregnenolone. None of the zones of the adrenal cortex expresses 3ß-HSD before 23 wks of gestation and it is generally assumed that the fetus does not produce cortisol de novo until about 30 wks [2]. Excluding a recently described short period in the first trimester [3] fetal cortisol production depends on supply of progesterone by the placenta to bypass 3ß-hydroxysteroiddehydrogenase [2].

*Corresponding author: Jan De Laffolie, Justus Liebig University, Department of General Pediatrics and Neonatology, Feulgenstr 1235392 Giessen, Germany, Tel: +49-641985-43400, Fax: +49-641-985-43419

Accepted: October 25, 2018;

Published online: October 27, 2018

Citation: Laffolie JD, Kästner L, Hartmann MF, et al. (2018) Enzyme Activity of $3 ß-H S D$ and $11 ß-H S D$ as Important Indicators of Steroid Bio-Synthesis and Inactivation in Preterm Infants. Adv Transl Med Res 1(1):16-22

Copyright: (c) 2018 Laffolie JD. This is an open-access article distributed under the terms of the Creative Commons Attribution License, which permits unrestricted use, distribution, and reproduction in any medium, provided the original author and source are credited. 
Citation: Laffolie JD, Kästner L, Hartmann MF, et al. (2018) Enzyme Activity of 3ß-HSD and 11ß-HSD as Important Indicators of Steroid Bio-Synthesis and Inactivation in Preterm Infants. Adv Transl Med Res 1(1):16-22

Furthermore, elevated cortisol precursor concentrations suggested immaturity of ad-renal 21-hydroxylase (21HYD) and 11ß-hydroxylase (11ßHYD) activity [4-7].

$17 \alpha$-Hydroxylase (17a-HYD) is a key enzyme at the beginning of the steroid biosynthesis and catalyzes pregnenolone to $17 \alpha$-hydroxypregnenolone and progesterone to $17 \alpha$-hydroxyprogesterone. This enzyme is expressed in the fetal and transitional but not in the definite zone of the fetal adrenal cortex [8].

Finally, cortisol inactivation by $11 ß$-hydroxysteroid dehydrogenase differs substantially before and after birth.

Intrauterinely, cortisol is inactivated by $80 \%$ presumably to protect the fetus against high glucocorticoid exposure [9]. Inactivation of cortisol is already reduced at the end of gestation resulting in increasing cortisol production by the term infant to prepare for delivery $[10,11]$. Thus, cortisol/cortisone ratio regulated by $11 ß$-hydroxysteroid dehydrogenase must be taken into account, too.

These investigations require determination of the full spectrum of steroid hormone metabolites. Steroid determination by gas chromatography-mass spectrometry (GC-MS) in 24-h urinary specimens enables noninvasive assessment of hormonal production rates and of single steroid metabolites as an integral measure of adrenal function $[12,13]$.

In contrast, discrete sampling of plasma steroid metabolite concentrations does not reflect the amount of steroids secreted in a 24-hour period. Using GC-MS urinary steroid profiling precursor/product ratio assessments can be measured simultaneously allowing the characterization of steroidogenic enzyme activities [14].

Cortisol production rates (CPR) determined by GCMS correlated negatively with gestational age, i.e. in the most immature infants the highest CPR were determined which were comparable with CPR in adults [15-17]. But, only in the more mature infants, CPR was influenced by severity of neonatal illness $[15,17]$. However, these findings suggest immature regulation but fully functional adrenal glucocorticoid biosynthesis in preterm infants.

To evaluate the maturation of postnatal adrenal steroidogenesis we determined the urinary steroid profiles by GC-MS in 142 preterm infants to characterize the activity of 3ß-hydroxysteroiddehydrogenase and 11ß-hydroxysteroid dehydrogenase from birth until discharge. We hypothesized that steroidogenic enzyme activity is not restricted in terms of preterm birth.

\section{Patients and Methods}

The Ethics Committee of the University of Giessen approved the study and written informed parental consent was obtained.

\section{Patients}

The study population consisted of preterm infants enrolled originally in a prospective longitudinal studies to investigate adrenal steroid production by GC-MS in relation to illness and postnatal growth $[15,17]$. The infants were born in Giessen University Hospital between July 2001 and November 2002.

Preterm infants with a gestational age $<37$ weeks were eligible for the study. Exclusion criteria included a family history of adrenal illnesses, major congenital anomalies (except atrial septum defect type II), and postnatal steroid therapy. Gestational age was determined using the expanded Ballard score and/or obstetrical dating. A prenatal betamethasone therapy was recorded as being complete if 2 doses of $12 \mathrm{mg}$ betamethasone were given to the mother more than $24 \mathrm{~h}$ antepartum.

Patients were included in the "ill preterm infants" IPI group in accordance with our previous studies $[18,19]$, if severe $\mathrm{RDS}\left(\mathrm{FiO} 2>0.4, \mathrm{tcSPO}_{2}<88 \%\right.$ ), perinatal or nosocomial infection $(\mathrm{CrP}>10 \mathrm{mg} / \mathrm{l}$ or neutrophile-shift within 72 hours of admission or after 72 hours with clinical signs of infection), intraventricular hemorrhage > second grade, or arterial hypotension was observed within $24 \mathrm{~h}$ before and after specimen was obtained. Otherwise they were categorized well preterm infants WPI. To assess the severity of illness, all infants were scored using the Score for Neonatal Acute Physiology (SNAP) on each day when urinary steroid metabolites were determined [20].

Patient data was recorded on inclusion in the study: gestational age, sex, birth weight, APGAR after five minutes, SGA status (weight $<3^{\text {rd }}$ percentile), prenatal steroid therapy, and SNAP score. The relevant data was also obtained on the days of measurement. Diagnoses were completed after discharge in the study documentation.

\section{Urine collection procedure}

Samples were taken on days one, two, three and five within the first week of life, afterwards weekly for four weeks and thereafter monthly until discharge. The urine collection procedure has been described recently [16]. In brief, urine was collected in special cellulose-only diapers in 2 sizes (weight $16 \mathrm{~g}$ in preterm infants below $2300 \mathrm{~g}$, $22 \mathrm{~g}$ above) (Pampers, Procter \& Gamble, Schwal-bach, Germany). Weighing the nappies before and after urine collections allowed exact calculation of 24-h urine output. Diapers were changed as necessary or at $4-8$ hours the latest. To reduce contamination with meconium or stool to a minimum, a thin gauze was placed between the baby's skin and the surface of the inner side of the nappy, thus, allowing urine to pass through the gauze and, at the same time, withholding meconium or stool, which then 
Table 1: Formulas for enzyme activity ratios. The formulas are derived from previous calculations, dividing the substrate concentrations by product concentrations, which correlate inversely with enzyme activity in 3ß-HSD.

\begin{tabular}{|c|c|}
\hline $3 ß-H S D$ & $\mathrm{DHEA}^{*} 100 / \mathrm{THE}+\alpha-\mathrm{CL}+\beta-\mathrm{CL}$ \\
\hline 11ß-HSD & ¿11-hydroxy-metabolites/ $\Sigma 11-k e t o-m e t a b o l i t e s$ \\
\hline
\end{tabular}

\section{3ß-Hydroxysteroid-Dehydrogenase}

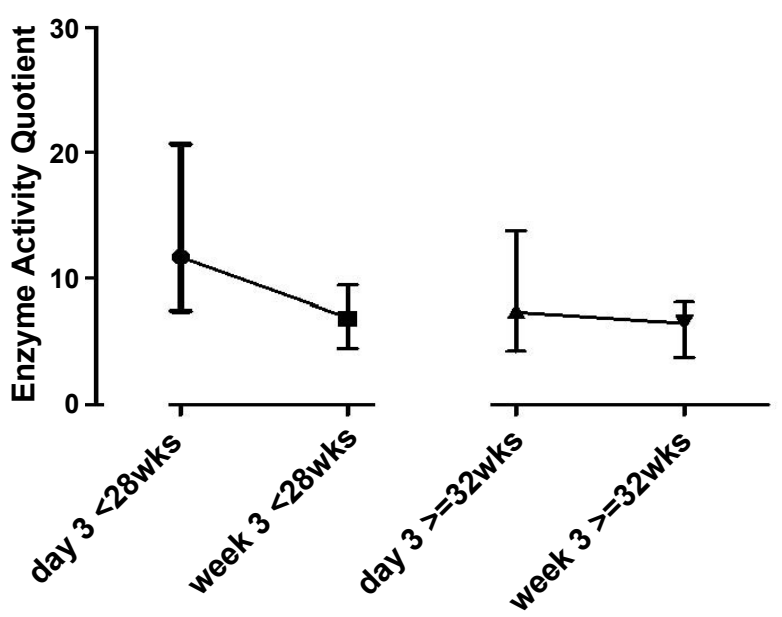

Figure 1: $3 ß-H S D$ Day 3 vs. Weeks $3 / G A<28$ weeks vs. $>=32$ weeks.

$3 ß-H S D$ activity quotient compared between third day of life vs. third week of life and gestational age $<28$ weeks vs. $>=$ 32 weeks (n.s.). Keep in mind that the activity quotient (substrate/products) is invers to enzyme activity. $3 ß-H S D$ activity increases only in preterm infants $<28$ weeks.

could easily be separated from the nappy. Samples from infants with diarrhea were omitted. Urine was extracted by compressing the nappies using a hydraulic press applying a maximum of $120 \mathrm{kPa} / \mathrm{cm}^{2}$. After centrifugation, the collected urinary specimens were stored at $-80^{\circ} \mathrm{C}$ until analysis by GC-MS.

\section{Laboratory analyses}

Urinary steroid profiles were determined by GC-MS analysis according to our procedure described recently [16]. The following steroid metabolites were determined by selected ion monitoring: 11-hydroxy-metabolites (cortisol): cortisol (F); 6ß-OH-cortisol (6ß-OH-F); tetrahydrocortisol (THF), allotetrahydrocortisol (aTHF); $ß$-cortol ( $\beta$-C); $\alpha$-cortol ( $\alpha$-C); 11-keto-metabolites (cortisone): tetrahydrocortisone (THE); $1 ß-\mathrm{OH}$-tetrahydrocortisone (1ß-OH-THE); $6 \alpha-\mathrm{OH}$-tetrahydrocortisone (6a-OH-THE); $\alpha$-cortolone ( $\alpha-\mathrm{CL}) ; 6 \alpha-\mathrm{OH}-\alpha$-cortolone (6a-OH- $\alpha-\mathrm{CL}) ; \beta$-cortolone ( $\beta-\mathrm{CL}) ; 1 ß-\mathrm{OH}-\beta$-cortolone (1ß-OH-ß-CL); 6a-OH-ß-cortolone (6a-OH-ß-CL); other steroid metabolites: tetrahydro-11-deoxycortisol (THS); dehydroepiandrosterone (DHEA); 16a-OH-dehydroepiandrosterone (16a-OH-DHEA); pregnanetriol (PT); pregnanentriolone(P5-olon-5ß,3a); 16a-OH-preg- nenolone (16a-OH-P5-olone); 15ß,17 $\alpha-\mathrm{OH}-$ pregnenolone (15ß,17a-OH-P5-olone). To assess overall cortisol secretion, 14 major urinary glucocorticoid metabo-lites were quantified (peak area integration) and summed. Daily urinary excretion rates of glucocorticoids were corrected for body weight and per $\mu \mathrm{mol}$ creatinine to take into account changes in glomerular filtration rate especially during the first week of life [16].

From the metabolite concentrations precursor/product ratios were calculated based on the formulas developed by Caulfield, et al. for CAH diagnosis as displayed in (Table 1) [14]. The ratio characterizing activity correlates inversely with enzyme activity.

\section{Statistics}

The data was processed in Microsoft Excel and analyzed using SAS Vers 8, (SAS Institute, Cary, USA). Since even after log transformation concentrations of glucocorticoid metabolites were not normally distributed, distributions of the variables of interest were given as median, range, and interquartile range. All inter-group differences were compared with the Mann-Whitney U test for continuous variables and the Fisher's exact test for categorical data.

To investigate the influence of postnatal age, day 3 and week 3 were chosen for statistical analysis by visual inspection of the graphical curves to identify the points of measurement with highest differences (Figure 1). Besides this, the decision was influenced by two more issues: a) To minimize the influence of postnatal stabilization of renal function, and b) To have a sufficient number of patients in the group of preterm infants $>32 \mathrm{wks}$ gestational age before discharge.

Then, a three-factorial design was chosen to analyze the influence of gestational age, postnatal age and illness on enzyme ratios. Because illness (well or ill) showed no influence, the design was switched to a two-factorial analysis. Because of the non-parametric distribution of the variables (even after various transformations including $\log$ transformation), analysis of variance was not appropriate and the following approach was used. To analyze interactions between factor gestational age group $(<$ 28 wks vs. $>=32$ wks GA) and the factor time (postnatal age at 3 days and 3 wks) the change over time was tested using the Wilcoxon-Mann-Whitney test. The global time effect was tested by the Wilcoxon-signed-rank test using the difference of ratios at week 3 and day 3. The global group effect was analyzed by Wilcoxon-Mann-Whitney test using the sum of the ratios at day 3 and week 3 . Under the assumption that there is no interaction, nor group or time effect, analysis was done in explorative sense. Therefore, the computed $\mathrm{p}$-values are a measure of the reproducibility of the results. 
Table 2: Group Characteristics-Disease Groups (a)/Gestational Age Groups (b).

a) Comparison of Group Characteristics for well preterm infants (WPI) and ill preterm infants (IPI).

\begin{tabular}{|c|c|c|c|}
\hline & WPI $(n=74)$ & IPI (n= 68) & $\mathbf{P}$ \\
\hline Gestational age (wks) $^{*}$ & $32.7(24-36.9)$ & $28.1(23.5-35.6)$ & $<0.0001^{\#}$ \\
\hline Birthweight/g* & $1825(640-2920)$ & $1095(457-2700)$ & $<0.0001^{\#}$ \\
\hline $\operatorname{Sex}(m / f)$ & $31 / 45$ & $29 / 39$ & $0.86^{\# \#}$ \\
\hline SGA & $6(8 \%)$ & $7(10 \%)$ & $0.77^{\# \#}$ \\
\hline Antenatal Steroid Completed & $31(44 \%)$ & $31(48 \%)$ & $0.61 \#$ \\
\hline Antenatal Steroids total & $40(56 \%)$ & $47(72 \%)$ & $0.083^{\# \#}$ \\
\hline Sectio ces. & $67(88 \%)$ & $60(88 \%)$ & $1.0^{\#}$ \\
\hline Cord Art $\mathrm{pH}^{*}$ & $7.32(7.14-7.44)$ & $7.31(7.12-7.62)$ & $0.75^{\#}$ \\
\hline 5-Min.-APGAR* & $9(5-10)$ & $8(1-10)$ & $0.0006^{\#}$ \\
\hline
\end{tabular}

b) Group characteristics by gestational age.

\begin{tabular}{|l|l|l|l|}
\hline & $<\mathbf{2 8}$ wks GA $\mathbf{n = 5 3}$ & >= 32 wks GA $\mathbf{~ n = 6 7}$ & p \\
\hline Gestational Age & $27(24+3-27+6)$ & $33.6(32+0-36+6)$ & $<0.0001^{\#}$ \\
\hline Birthweight/g* & $920(460-1400)$ & $2040(1220-2920)$ & $<0.0001^{\#}$ \\
\hline Sex $(\mathrm{m} / \mathrm{f})$ & $26 / 27$ & $46 / 21$ & $0.0657^{\# \#}$ \\
\hline SGA & $4(7.5 \%)$ & $8(12 \%)$ & $0.6812^{\# \#}$ \\
\hline Antenatal steroids total & $4(87 \%)$ & $26(42 \%)$ & $0.0040^{\# \#}$ \\
\hline C-sectio & $45(85 \%)$ & $60(90 \%)$ & $0.6658^{\# \#}$ \\
\hline Cord art pH & $7.30(7.12-7.46)$ & $7.32(7.2-7.62)$ & $0.5698^{\#}$ \\
\hline 5-Min.-APGAR & $8(5-10)$ & $9(1-10)$ & $0.0056^{\#}$ \\
\hline
\end{tabular}

"Median (Minimum-Maximum); "Mann-Whitney-U-Test; "\#Fisher's exact test.

\section{Results}

\section{Patients}

142 preterm infants were included, 74 into the well preterm infant group (WPI), 68 patients into the ill preterm infants group (IPI).

\section{Group characteristics ill vs. well preterm infants}

Comparing IPI and WPI groups, IPI were earlier in gestational age, had lower birth weight and a lower 5-Min-APGAR (Table 2).

Five patients died before discharge in the IPI group. In terms of diagnosis, IPI showed more infections (47\% vs. $0 \%, \mathrm{p}<0.0001)$, RDS ( $84 \%$ vs. $46 \%, \mathrm{p}<0.0001)$, BPD, defined as $\mathrm{FiO}_{2}>21 \%$ on day $28,(33 \%$ vs. $3 \%$, p < 0.0001 ), PDA ( $45 \%$ vs. $12 \%, \mathrm{p}<0.0001$ ), NEC ( $8 \%$ vs. $0 \%$ $\mathrm{p}=0.018)$ and IVH ( $30 \%$ vs. $9 \%, \mathrm{p}=0.0023)$. There was no significant difference in ROP ( $3 \%$ vs. $8 \% \mathrm{p}=0.11)$. SNAP Score values were significantly higher for IPI than WPI during the first four weeks ( $\mathrm{p}=0.0002)$.

A three factorial analysis yielded no significant influence of severity of disease, so analysis continued two-factorial for gestational and postnatal age and influence on longitudinal data.

Longitudinal data and two-factorial analysis for gestational age ( $<28 \mathrm{vs} .>=32 \mathrm{wks})$ and postnatal age (day 3 vs. week 3 ) on enzyme activity

$3 ß$-hydroxysteroiddehydrogenase activity showed an increase from day 3 to week 3 in preterm infants $<28$

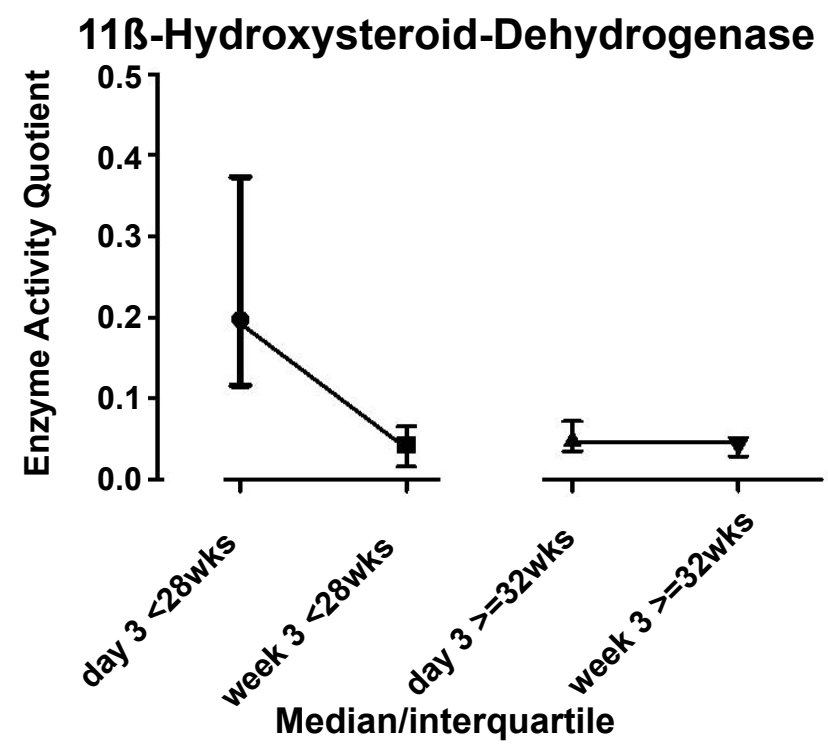

Figure 2: 11ß-Hydroxysteroid-Dehydrogenase-Cortisol Inactivation.

Preterm infants $<28$ weeks have a significant lower $11 ß-\mathrm{Hy}-$ droxysteroid-Dehydrogenase activity on day 3 compared to more mature preterms resulting in higher active cortisol levels. This difference is not found after 3 weeks of life.

weeks GA compared to infants $>=32$ wks GA (Figure $2)$. This was confirmed by stastical analysis $\left(\mathrm{p}_{\text {time } \times \text { group }}=\right.$ $0.019)$.

$11 ß$-hydroxysteroid dehydrogenase inactivates cortisol to cortisone. Figure 3 shows a shift towards active cortisol metabolites during the first week of life in preterm infants $<28$ weeks, but activity moved to the 


\section{3ß-Hydroxysteroid-Dehydrogenase}

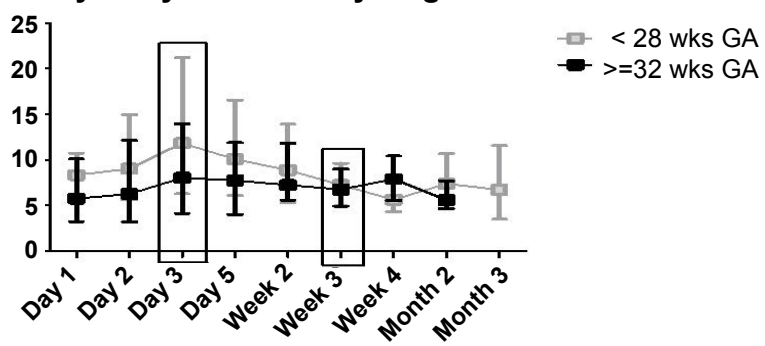

11ß-Hydroxysteroid-Dehydrogenase

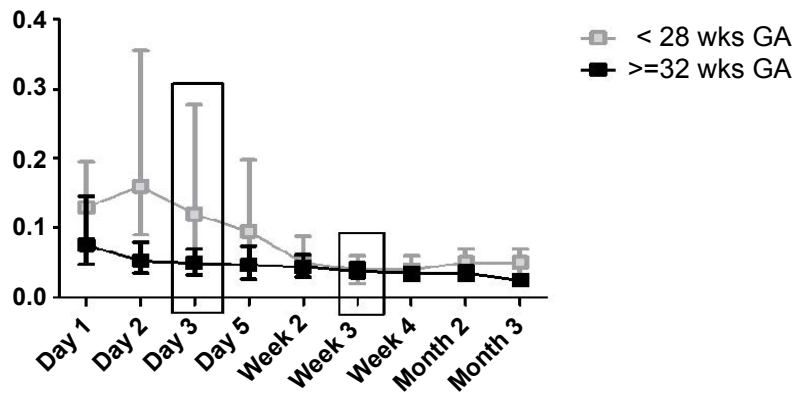

Figure 3: Longitudinal data on enzyme activity $3 ß-H S D$ (top) and 11ß-HSD (bottom).

Light line for preterms $<28$ weeks gestational age, dark line $>=32$ weeks gestational age.

SNAP Score by Gestational Age

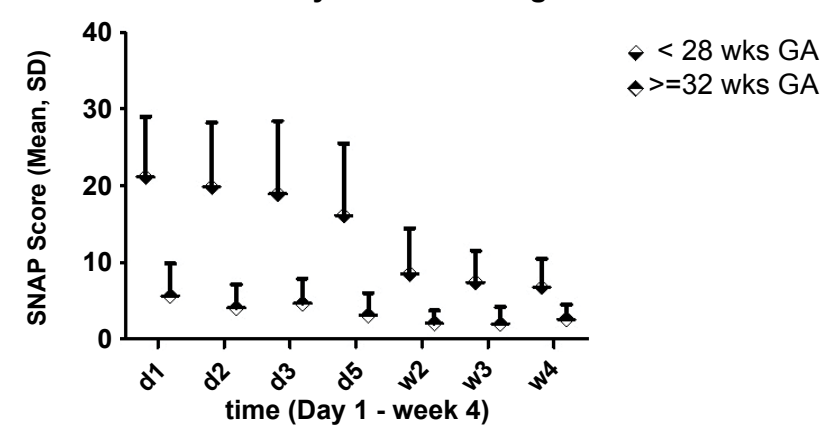

Figure 4: SNAP Score longitudinal compared between the gestational age groups.

Top line $<28$ weeks gestational age, bottom line $>=32$ weeks gestational age group (mean, SD).

level of preterm infants $>32$ weeks thereafter. Again, this was confirmed by two-factorial analysis (Figure 3 ; $\mathrm{p}_{\text {time } x}$ group $<0.001)$.

Preterm infants $<28$ wks GA had, as expected, significantly higher SNAP scores for all observation time points (Figure 4).

3ß-hydroxysteroiddehydrogenase activity was lower on days two and three, while the lower values for day one and five and week 2 were not statistically significant (Figure 1).

In direct comparison, 11ß-hydroxysteroid dehydrogenase activity was significantly lower in preterm infants
$<28$ weeks than in infants $>=32$ weeks on days 1 to 5 (Figure 1).

While there was no significant correlation of $3 ß$-hydroxysteroiddehydrogenase with SNAP scores at any time, there was a significant inverse correlation of cortisol inactivation and SNAP scores on days one to five (spearman correlation; day $1 \mathrm{R}=0.30, \mathrm{p}=0.007 ; \mathrm{d} 2: \mathrm{r}=$ $0.54, \mathrm{p}<0.001 ; \mathrm{d} 3: \mathrm{r}=0.51, \mathrm{p}<0.001 ; \mathrm{d} 5: \mathrm{r}=0.40, \mathrm{p}<$ $0.001)$.

\section{Discussion}

\section{Limitations of the study}

The three-factorial approach initially taken was difficult, because using ratios, variance in both influencing variables with exponentially increase in variance analysis of ratios.

\section{Strengths of the study}

The collection method used in this study has been validated before including excellent retrieval of metabolites from the urine [16].

A single cortisol serum measurement is less valuable, since a wide fluctuation of values dependent on various situational influences can be expected [12,21].

The calculation of enzyme activity through substrate/ product quotas was successfully used by Caulfield, et al. [14] including the used formulas.

Previous literature to glucocorticoid metabolism in preterm infants is scarce.

Scott, et al. [22] found an increase in serum cortisol levels in very preterm infants postnatal. This can be contributed to stress to the infant on a NICU, also their data lack longitudinal information.

Wittekind, et al. [23] found decreasing cortisol levels for 8 weeks in serum. Serum cortisol levels, however, are unreliable, since they do not represent the overall cortisol production rate and are highly influenced by factors as nutritional status, current vegetative state and other internal and external influences.

When comparing overall cortisol production rate with disease severity in previous studies $[15,17]$ we found no significant correlation in preterm infants $<30$ wks GA and a weak correlation $>30$ wks.

A significant $3 ß-H S D$ activity increase was only observed in preterm infants $<28$ weeks from first until third week of life. This matches intrauterine development where 3ß-hydroxysteroiddehydrogenase is by far less active [24], leading to mainly DHEAS production, although some activity is measurable in an early gestational period around 8 weeks GA [3]. Thus, we consider 
Citation: Laffolie JD, Kästner L, Hartmann MF, et al. (2018) Enzyme Activity of 3ß-HSD and 11ß-HSD as Important Indicators of Steroid Bio-Synthesis and Inactivation in Preterm Infants. Adv Transl Med Res 1(1):16-22

this data a physiologic maturation process. We further found no correlation with severity of disease. Recent data from Nykänen, et al. [25] suggest that $3 ß$-hydroxysteroiddehydrogenase activity is not the limiting factor in preterm adrenal insufficiency.

$11 ß-H S D$ activity index was higher initially in the group $<28$ weeks on the first days of life (day two and three), declining afterwards to the level of the more mature infants.

In utero, $11 ß$-HSD is very important for inactivation of most cortisol, creating a developmental environment with low cortisol and relatively high cortisone metabolites. In extrauterine life, decreasing enzyme activity is a known adaption mechanism to disease/stress in adults [26].

We could find a significant correlation between shift to active cortisol and SNAP scores for day one to three. Therefore extrauterine adaption with down-regulation is mandatory to provide adequate active cortisol, especially in the first days of life.

To conclude, we found enzyme activity in preterm $<28$ wks GA significantly different from more mature patients. While the increase in 3ß-HSD activity was not correlated with severity of disease or SNAP scores and indicates physiological maturation processes, we could demonstrate a correlation with 11ß-HSD activity. A shift towards active cortisol with less inactivation seems to be an important mechanism for cortisol adaption during the first days of life in preterm infants.

\section{References}

1. Fernandez EF, Watterberg KL (2009) Relative adrenal insufficiency in the preterm and term infant. Journal of perinatology 2: 44-49.

2. Mesiano S, Jaffe RB (1997) Developmental and functional biology of the primate fetal adrenal cortex. Endocr Rev 18: 378-403.

3. Goto K, Yanase T, Takayanagi R, et al. (2006) Adrenal androgen and bone metabolism. Clinical calcium 16: 429-435.

4. Al Saedi S, Dean H, Dent W, et al. (1995) Reference ranges for serum cortisol and 17-hydroxyprogesterone levels in preterm infants. The Journal of Pediatrics 126: 985-987.

5. Hingre RV, Gross SJ, Hingre KS, et al. (1994) Adrenal steroidogenesis in very low birth weight preterm infants. The Journal of clinical endocrinology and metabolism 78: 266270.

6. Lee MM, Rajagopalan L, Berg GJ, et al. (1989) Serum adrenal steroid concentrations in premature infants. The Journal of clinical endocrinology and metabolism 69: 1133-1136.

7. Watterberg KL, Gerdes JS, Cook KL (2001) Impaired glucocorticoid synthesis in premature infants developing chronic lung disease. Pediatr Res 50: 190-195.

8. Mesiano S, Jaffe RB (1993) Interaction of insulin-like growth factor-II and estradiol directs steroidogenesis in the human fetal adrenal toward dehydroepiandrosterone sulfate production. J Clin Endocrinol Metab 77: 754-758.

9. Pasqualini JR, Marfil J, Garnier F, et al. (1970) Studies on the metabolism of corticosteroids in the human foeto-placental unit. 4. Metabolism of deoxycorticosterone and corticosterone administered simultaneously into the intact umbilical circulation. Acta Endocrinol (Copenh) 64: 385-397.

10. Donaldson A, Nicolini U, Symes EK, et al. (1991) Changes in concentrations of cortisol, dehydroepiandrosterone sulphate and progesterone in fetal and maternal serum during pregnancy. Clin Endocrinol (Oxf) 35: 447-451.

11. Sippell WG, Becker H, Versmold HT, et al. (1978) Longitudinal studies of plasma aldosterone, corticosterone, deoxycorticosterone, progesterone, 17-hydroxyprogesterone, cortisol, and cortisone determined simultaneously in mother and child at birth and during the early neonatal period. I. Spontaneous delivery. J Clin Endocrinol Metab 46: 971-985.

12. Kraan GP, Dullaart RP, Pratt JJ, et al. (1998) The daily cortisol production reinvestigated in healthy men. The serum and urinary cortisol production rates are not significantly different. J Clin Endocrinol Metab 83: 1247-1252.

13. Zumoff B, Fukushima DK, Hellman L (1974) Intercomparison of four methods for measuring cortisol production. $J$ Clin Endocrinol Metab 38: 169-175.

14. Caulfield MP, Lynn T, Gottschalk ME, et al. (2002) The diagnosis of congenital adrenal hyperplasia in the newborn by gas chromatography/mass spectrometry analysis of random urine specimens. J Clin Endocrinol Metab 87: 3682-3690.

15. Heckmann M Matthias, Michaela F Hartmann, Birgit Kampschulte, et al. (2005) Cortisol production rates in preterm infants in relation to growth and illness: A noninvasive prospective study using gas chromatography-mass spectrometry. Journal of Clinical Endocrinology \& Metabolism 90: 5737-5742.

16. Heckmann M, Hartmann MF, Kampschulte B, et al. (2005) Assessing cortisol production in preterm infants: Do not dispose of the nappies. Pediatr Res 57: 412-418.

17. Grofer B, Bodeker RH, Gortner L, et al. (2010) Maturation of adrenal function determined by urinary glucocorticoid steroid excretion rates in preterm infants of more than 30 weeks of gestational age. Neonatology 98: 200-205.

18. Heckmann M, Wudy SA, Haack D, et al. (1999) Reference range for serum cortisol in well preterm infants. Arch Dis Child Fetal Neonatal Ed 81: 171-174.

19. Heckmann M, Wudy SA, Haack D, et al. (2000) Serum cortisol concentrations in ill preterm infants less than 30 weeks gestational age. Acta Paediatr 89: 1098-1103.

20. Richardson DK, Gray JE, McCormick MC, et al. (1993) Score for Neonatal Acute Physiology: A physiologic severity index for neonatal intensive care. Pediatrics 91: 617-623.

21. Heckmann M, Hartmann MF, Kampschulte B, et al. (2006) Persistent high activity of the fetal adrenal cortex in preterm infants: Is there a clinical significance? J Pediatr Endocrinol Metab 19: 1303-1312.

22. Scott SM, Rogers C, Backstrom C (1995) Dexamethasone therapy is associated with a rise in urinary epidermal growth factor concentrations in the preterm infant. Eur J Endocrinol 132: 326-330. 
Citation: Laffolie JD, Kästner L, Hartmann MF, et al. (2018) Enzyme Activity of 3ß-HSD and 11ß-HSD as Important Indicators of Steroid Bio-Synthesis and Inactivation in Preterm Infants. Adv Transl Med Res 1(1):16-22

23. Wittekind CA, Arnold JD, Leslie GI, et al. (1993) Longitudinal study of plasma ACTH and cortisol in very low birth weight infants in the first 8 weeks of life. Early Hum Dev 33: $191-200$.

24. Doody KM, Carr BR, Rainey WE, et al. (1990) 3 beta-hydroxysteroid dehydrogenase/isomerase in the fetal zone and neocortex of the human fetal adrenal gland. Endocrinology 126: 2487-2492.
25. Nykanen P, Heinonen K, Riepe FG, et al. (2010) Serum concentrations of adrenal steroids and their precursors as a measure of maturity of adrenocortical function in very premature newborns. Horm Res Paediatr 74: 358-364.

26. Vogeser M, Felbinger TW, Roll W, et al. (1999) Cortisol metabolism in the postoperative period after cardiac surgery. Exp Clin Endocrinol Diabetes 107: 539-546. 